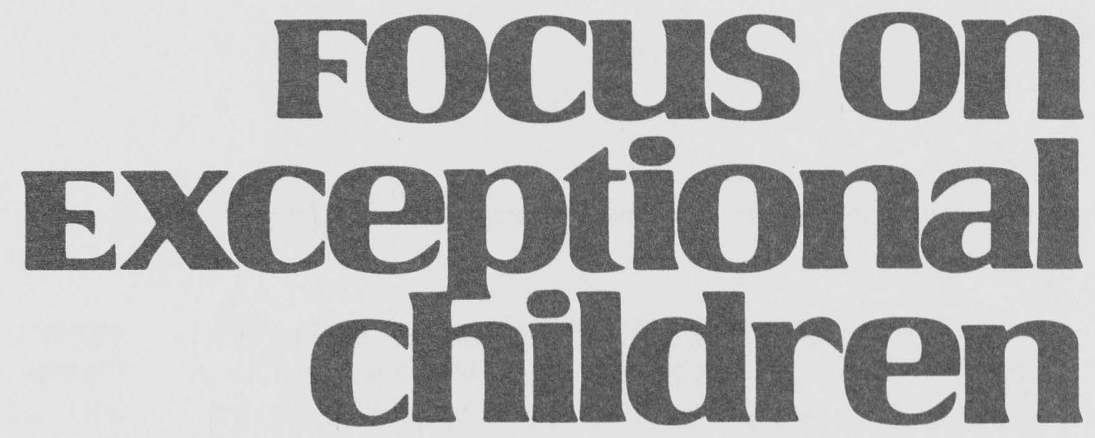

\title{
Classroom Interventions for Students With Attention Deficit Disorders
}

\author{
Karen J. Rooney
}

To work effectively with students with attention disorders in the classroom, a diagnostic/prescriptive approach is necessary for the teacher to understand the student and develop appropriate interventions. The disorder increases the complexity of the teaching process because the attentional problems result in gaps in learning, different processing styles, and behaviors that interfere with learning and academic performance. For example, Jimmy was sitting in class listening to a lesson on farm animals. His reaction to the lesson was to ask his teacher if she had ever been to the Empire State Building, which certainly gave the impression that Jimmy had not been paying attention. The teacher responded, "Jimmy, why would you ask that question now?" Jimmy explained, "You were talking about farm animals, and my uncle used to have a farm that I visited every summer. Last year, he sold his farm and moved to New York City, so I went there instead of the farm, and he took me to the Empire State Building." Jimmy taught his teacher that students with attention disorders do not always process information the way their parents or teachers think they should and that behavior is not always what it seems to be.

During a well-intentioned spelling lesson, Sarah taught her teacher the second lesson, which demonstrates the necessity for ongoing monitoring and diagnostic teaching. Sarah's teacher taught her to use small words within words to help her with spelling. Sarah spelled the word brown as "brone." She was asked to identify a small word within brown to help her spell the word correctly. She identified the word "ow" in brown, and the teacher was quite satisfied until Sarah wrote "brone" on the retest. The teacher asked Sarah if she remembered the small word she had identified, and Sarah said, "Yes—-the word "ow." The teacher pointed to Sarah's word and queried, "Do you see "o-w" in brown?" Sarah gave the teacher an exasperated look and said, "Well, you didn't tell me that "c (see)-o-w" was in the word, so that's why I got it wrong."

Karen Rooney holds the Ph.D. from the University of Virginia and currently is director of the Learning Resource Center, Attention Disorders Clinic, Richmond, Virginia, a nonprofit program specializing in assessment and interventions for individuals with learning disabilities and attention disorders. 
Sarah taught her teacher that working with students with attention disorders is not always easy and that interventions have to take into account the individual's unique characteristics as well as the situation. No program or intervention will magically cure an attention disorder. An indepth understanding of the student's attention disorder is needed to develop classroom interventions that support attention, fill in gaps in learning, and provide feedback to the teacher for continuing and changing interventions. The use of descriptors to describe the attention disorder will help teachers understand the disorder better.

\section{DESCRIPTORS OF ATTENTION DISORDERS}

The definition of attention frequently has been described in generic terms as though attention were a singular construct, but the literature has not supported this approach (Goldstein \& Goldstein, 1990; Kietzman, Spring \& Zubin, 1980; Posner \& Snyder, 1975; Rosenthal \& Allen, 1978). In

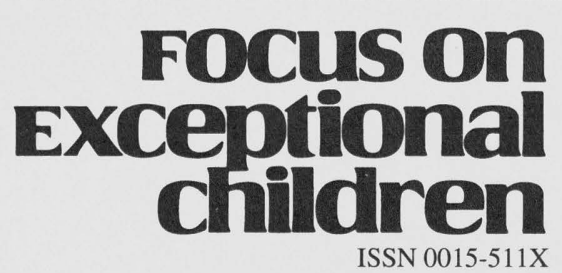

FOCUS ON EXCEPTIONAL CHILDREN (USPS 203-360) is published monthly except June, July, and August as a service to teachers, special educators, curriculum specialists, administrators, and those concerned with the special education of exceptional children. This publication is annotated and indexed by the ERIC Clearinghouse on Handicapped and Gifted Children for publication in the monthly Current Index to Journals in Education (CIJE) and the quarterly index, Exceptional Children Education Resources (ECER). It is also available in microfilm from Xerox University Microfilms, Ann Arbor, MI. Subscription rates: Individual, $\$ 30$ per year; institutions, $\$ 40$ per year. Copyright (C) 1993, Love Publishing Company. All rights reserved. Reproduction in whole or part without written permission is prohibited. Printed in the United States of America. Second class postage is paid at Denver, Colorado. POSTMASTER: Send address changes to:

Love Publishing Company

Executive and Editorial Office

1777 South Bellaire Street

Denver, Colorado 80222

Telephone (303) 757-2579

Edward L. Meyen

University of Kansas

Glenn A. Vergason Georgia State University

Richard J. Whelan

University of Kansas Medical Center

Stanley F. Love

Publisher
Holly T. Rumpler

Senior Editor contrast, Postle (1988) described attention as "the process through which we construct the world we experience." Thus, a multifactorial definition of attention is necessary for understanding the construct (Halperin et al., 1990). In spite of this data, when a child is diagnosed as having an attention deficit, little attention is given to the description of the attention problems involved. Typically, the diagnosis of attention deficit disorder is treated as a definitive, singular construct as though the label will explain the individual's disorder. Subtype descriptors can prevent the oversimplification of a complicated construct and make the diagnosis of an attention disorder a more salient description that can be translated into appropriate educational and behavioral interventions.

Attention can be divided into two categories that describe specific types of attentional weaknesses: (a) encoding, or problems with incoming stimuli and the storage of this stimuli for processing; and (b) the selection of stimuli to process further.

\section{Encoding}

Attention span refers to the length of time an activity is pursued. Switching from task to task without completing the task is one example of a weakness in attention span. A child is not able to continue attending long enough to complete the task or process successfully.

Focusing attention refers to the ability to tune out distracting or irrelevant stimuli so attention is directed toward the appropriate stimuli. This type of attention deficit is exacerbated as the complexity of the task increases (Kietzman et al., 1980; Zentall, 1983).

Divided attention refers to the ability to split attention between two or more inputs or aspects of a task. Impairment in the ability to "split" or allocate attention results in deterioration in speed and accuracy of attentional processing (Kietzman et al., 1980). If a teacher is giving an example of gravity by describing a ride at an amusement park, the attention should focus on the message, and distracting, irrelevant conversations or environmental noises have to be ignored. Focused attention requires the elimination of distracting or irrelevant stimuli. For example, if a teacher is demonstrating a math problem and teaching the steps verbally, the student has to divide or allocate attention between the problem being worked and the message being delivered.

Sustained attention is the ability to maintain the focus of attention over time and is related to arousal or activation of the nervous system. Kahnehan (1973) stated that arousal is the amount of effort required for attentional processing. If arousal is low, motivation, alertness, and processing capac- 
ity are diminished and sustained attention is impaired. Many students with ADD become fatigued because of the greater demands on energy when they process information or pay attention.

Intensity of attention has been shown to have an influence on focus as well as memory storage (Pettijohn, 1987). The greater the intensity of the attention from factors such as interest, motivation, or novelty, the greater is the ability to focus and sustain attention. Weaknesses in intensity are similar to widespread underarousal, which interferes with attentional processing capacity. Research on students with ADD indicates that the students perform better under novel, highly stimulating conditions and less well under routine, boring conditions (Zentall, 1983).

Sequential attention is the ability to focus attention on the stimuli in the order necessary to successfully complete the task or accurately comprehend the information. For example, if instructions are being given, attention must be directed to the stimuli in correct order for accurate comprehension and execution to take place. Accuracy of sequential attention affects comprehension of behavioral situations as well as academic processing because of the importance of sequential order in comprehension, application, and generalization.

\section{Selection}

Selective attention is the ability to choose the appropriate stimuli for processing. After attention is focused and sustained, certain pieces of information or stimuli are chosen for further processing. For example, in a textbook some terms are put in bold print to help students select these words, rather than other words in the text, for processing. Students with ADD have more difficulty than non-ADD students with the selection process (Hallahan \& Reeve, 1980). The concept of selective attention is important in terms of educational intervention because of its implications for studying and test-taking.

Involuntary attention is an automatic response to a stimuli. For example, if someone calls a person's name, the attentional response is immediate.

Voluntary attention is conceptually driven and refers to "the allocation of attention to stimuli that are relevant to current plans, expectations and intentions" (Kietzman et al., 1980). This type of attentional processing is intentional, deliberate, and conscious. The process of choosing relevant stimuli requires excessive energy and demands extensive practice but can become more automatic over time. Driving a car is an example of a task involving voluntary attention that becomes an automatic process. As the car leaves the motor vehicle department, the new driver is thinking of every detail related to the driving process, but with experience the driver can look at scenery, recognize familiar friends, and listen to the news while driving, without interference in the driving process.

Filtering is the process of weeding out irrelevant stimuli from relevant stimuli. Theories such as the "bottleneck" suggest that information is narrowed to the most critical stimuli. This filtering process also has been viewed in terms of "set." Schema set (Broadbent, 1971) is a filtering process that targets appropriate stimuli because of the physical properties of the stimuli.

A second filtering process called response set selects stimuli for further processing based on the similarity between the stimuli and the conceptual expectation. For example, if a child is told to attend to the teacher with the blue dress, the schema set controls the selection. If the child is told to attend to the teacher who is talking about space, the response set controls the selection. Because students with ADD have difficulty with schemas, the filtering process is complicated by the organizational weaknesses as well as the attentional focus.

The use of these descriptors of attention has been well documented in the literature. Encoding descriptors such as short-term/working memory deficits have been reviewed by Baddeley (1986), Torgeson, Kistner, \& Morgan (1987), and McIntyre, Murray, \& Blackwell (1981). Selective attention deficits have been analyzed from an educational perspective in some of the most interesting studies (Hallahan \& Reeve, 1980; Hallahan, Tarver, Kauffman, \& Graybeal, 1978; Richards, Samuels, Turnure \& Ysseldyke, 1990). An understanding of these descriptors of attentional disorders enables educators to understand the nature of the disorder as manifested in the individual so intervention planning will be a "better fit" and more successful.

\section{INTERVENTION PLANNING}

In regard to intervention planning, knowledge of two techniques for behavioral analysis and two important approaches to intervention can be useful. Behavioral observation and behavioral analysis are important techniques to enable a teacher to analyze a student's individual needs, as well as environmental dynamics that have to be addressed during intervention planning. In addition, behavior management and organizational training should be addressed in the intervention program. 


\section{Behavioral Observation}

Behavioral observation systems are valuable tools to collect information about a student's behavior. The techniques are simple and depict behavior over time so the practitioner can view the behaviors more objectively than with less structured approaches. Many checklists are available that can be used for assessment (Goldstein \& Goldstein, 1990), but observation is necessary to determine how the disorder presents itself in the individual student. The observational techniques discussed next represent some simple methods to obtain behavioral information.

\section{Strength/Weakness Chart}

A simple chart made from teacher perceptions of the individual's strengths and weaknesses can facilitate educational/ behavioral planning. Teacher comments often have less impact because the comments are narrative in nature and are not organized succinctly. The comments may be from current teachers or may be compiled from comments and/or grades in the student's cumulative record. Charts can clearly convey the perceptions of a teacher or multiple teachers concerning a student's strengths and weaknesses as well as the teachers' concerns. Solutions using the strengths can be generated for each weakness. An example of such a chart for a tenth-grader is given in Figure 1.

\section{Tracking Cards}

Tracking the frequency of the behaviors sometimes can be difficult for teachers who are actively involved in the teaching process. Easy access to a card with designated spaces representing specific behaviors may enable the teacher to record a quick checkmark as a frequency tally. Manipulatives such as moving the pieces of an abacus, moving colored macaroni from one container to another, or shifting rubberbands from one wrist to another are examples of creative substitutes for written tallies. The frequency number then is recorded on the daily card, and the data from daily cards can be graphed or tabulated to provide a more objective view of the severity of the problem and is useful for parent or student conferences. A second type of card simply makes a record of daily comments by the teacher. Examples of these cards are given in Figure 2.

\section{Time Sampling of Attention}

Attention has been defined as on-task behavior that can be measured through the use of a time-sampling method to identify the occurrence and nonoccurrence of on-task behavior representing attention (Hallahan, Lloyd, Kosiewicz, Kauffman, \& Graves, 1979; Hallahan, Kneedler, \& Lloyd, 1982; Rooney, Hallahan, \& Lloyd, 1984). Observing ontask behavior is particularly useful when looking at student

\section{Strengths \\ Discussion in class \\ Leader in cooperative learning \\ Oral responses \\ Multiple-choice tests \\ Memorization}

\section{Weaknesses}

Sustained attention

Fatigue

Written language

Essay tests

Integration

\section{Accommodations/Recommendations}

Oral test alternatives

Eliminate rote copying tasks

Frequent breaks

Practice essay questions

Use pictorials/diagrams for concepts

Use graphic organizers that force attention to detail and identification of the concept

Key word notetaking

Prepare study materials in cooperative learning groups

Use review systems consistently

Use multiple-choice tests with essays that have been organized in advance

FIGURE 1 
Narrative Cards

\section{November 10}

Sue had trouble starting her classwork immediately.

Sue had difficulty finishing her seatwork and had to take classwork home to finish.

Sue was involved in a disagreement on the playground. She and Marta fought over their turn on the swing. They were separated and put in time-out until they could control their behavior.

Did not have papers signed by parents.

\section{Quantitative Cards}

\begin{tabular}{|lcc|}
\hline Did Sue finish her work this week? & Yes & No \\
\hline Monday & & $\mathrm{x}$ \\
Tuesday & $\mathrm{x}$ & \\
Wednesday & $\mathrm{x}$ & \\
Thursday & & $\mathrm{x}$ \\
Friday & & $\mathrm{x}$ \\
& & \\
\hline
\end{tabular}

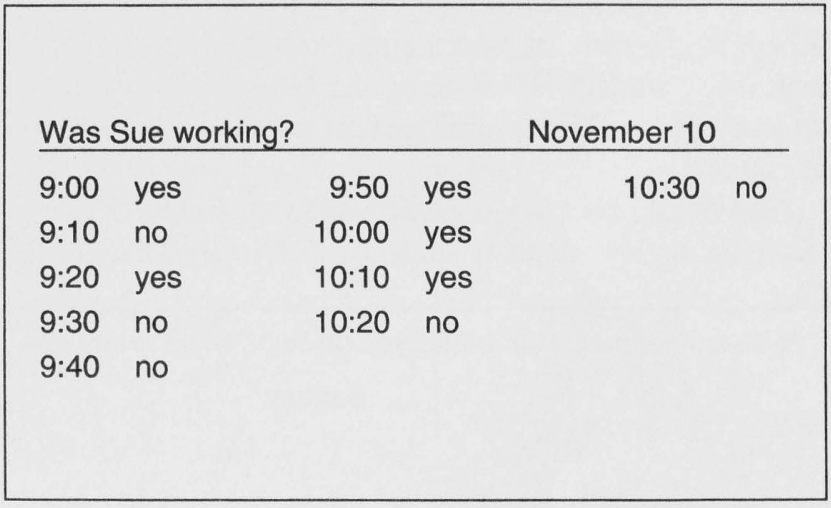

Was Sue working?

November 11

\begin{tabular}{|c|c|c|c|c|c|}
\hline 9:00 & yes & $9: 50$ & yes & $10: 30$ & no \\
\hline 9:10 & yes & $10: 00$ & no & & \\
\hline 9:20 & yes & $10: 10$ & no & & \\
\hline $9: 30$ & yes & $10: 20$ & no & & \\
\hline $9: 40$ & yes & & & & \\
\hline
\end{tabular}


levels of attention in the classroom. The task that will be observed is defined in behavioral terms so the definition of ontask behavior is clear. If the student is supposed to be reading a book, on-task behavior may be defined as eyes being on the book. If the student should be listening to the teacher, the student's eyes should be on the teacher. If a student should be writing, the pencil should be moving on the paper. The behavioral definitions make the judgments more objective, uniform, and accurate.

In addition to the target student, a sample of students is selected randomly. Usually the observational sample consists of five students, consisting of four randomly selected students plus the target student. Each student is given a number, and a recording sheet with the numbers of each child and Yes/No columns for each is created. The observer looks at each child at consistent intervals (i.e., every two seconds) and places a checkmark in the "yes" column if the student is on-task according to the behavioral criteria established for the task, or places a checkmark in the "no" column if the student is not doing the behavior identified by on-task criteria. The recording sheet may look like the one in Figure 3.

Behavioral observation systems are valuable tools to collect information about a student's behavior. These tech- niques are just a sample of simple observational techniques that depict behavior over time so the behaviors can be viewed more objectively, accurately, and systematically over time than with less structured approaches.

\section{Behavioral Analysis}

When observing students with attention disorders, visual organizers can facilitate the process of behavioral analysis. The organizers help focus attention on the dynamics of the behavior by forcing consideration of the situation prior to the occurrence of the behavior and after the occurrence of the behavior, which can change the intervention planning dramatically. For example, if the behavior of concern is that Bill yelled out in class, the intervention will be geared toward Bill, but if the analysis reveals that Steve punched Bill on the back first, the targets of the intervention should be both Steve and Bill.

Without sufficient analysis, even the target of the intervention can't even be identified accurately. If the analysis discloses that Bill yelled out and after class Bob and Sarah told him how funny he was when he yelled and dared him to do it again, the intervention should take into account the peer pressure that is causing the behavior to continue. Fig-

\begin{tabular}{|c|c|c|c|c|c|c|c|c|c|}
\hline \multicolumn{10}{|c|}{ Was Bob paying attention (eyes on book while reading)? } \\
\hline \multicolumn{2}{|c|}{ Bob } & \multicolumn{2}{|c|}{ Sammy } & \multicolumn{2}{|c|}{ Jonah } & \multicolumn{2}{|c|}{ Jonathon } & \multicolumn{2}{|c|}{ Francis } \\
\hline Yes & No & Yes & No & Yes & No & Yes & No & Yes & No \\
\hline$x$ & & $x$ & & $x$ & & $x$ & & $x$ & \\
\hline$x$ & & $x$ & & $x$ & & $x$ & & $x$ & \\
\hline$x$ & & $x$ & & & $x$ & $x$ & & $x$ & \\
\hline $\mathrm{x}$ & & $\mathrm{x}$ & & $x$ & & $x$ & & $x$ & \\
\hline$x$ & & $\mathrm{x}$ & & $x$ & & $x$ & & $x$ & \\
\hline & $x$ & $x$ & & $x$ & & $x$ & & $x$ & \\
\hline & $x$ & $x$ & & $x$ & & $x$ & & $x$ & \\
\hline$x$ & & & $x$ & $x$ & & $x$ & & $x$ & \\
\hline & $x$ & $x$ & & $x$ & & $x$ & & $x$ & \\
\hline & $x$ & $x$ & & $x$ & & $x$ & & $x$ & \\
\hline$x$ & & $x$ & & $x$ & & $x$ & & $x$ & \\
\hline$x$ & & $x$ & & & $x$ & & $x$ & $x$ & \\
\hline \multicolumn{10}{|c|}{ Percentages on-task: } \\
\hline \multicolumn{2}{|c|}{$67 \%$} & \multicolumn{2}{|c|}{$92 \%$} & \multicolumn{2}{|c|}{$83 \%$} & \multicolumn{2}{|c|}{$92 \%$} & \multicolumn{2}{|c|}{$100 \%$} \\
\hline
\end{tabular}


ure 4 gives examples of some visual organizers-the Three, Four, and Five Square approaches.

The situation prior to occurrence of the behavior must be identified to put the behavior in the appropriate context. In the situation depicted in Figure 4, Bill received a negative consequence and probably was angry because Jim started the episode but got away with it. Bill's anger likely will affect future interactions with the teacher. Jim likely will continue the behavior because he did not receive any consequence at all and probably enjoyed getting away with the kicking.

In the Three Square approach, the behavior is analyzed in its context to arrive at causative factors that are making the behavior occur or dynamics that are making the behavior continue. The fourth square generates solutions, and the fifth square tracks effective interventions for the individual student.

\section{Behavior Management}

Behavior management depends on the predictability of behavior, on the premise that people learn behavior, and on the assumption that programs can be devised to change behavior.

Two common behavior management formats used to change behavior must be examined in light of the characteristics used to describe attention disorders. The first format is geared to the individual: Mrs. Jones, the teacher, would like Jane to volunteer more often in class. She sets up a system that will give Jane a star on a chart taped to her desk each time she volunteers for an answer. When Jane has all 10 squares filled in on the chart, she will earn a special eraser for her pencil.

The second format, called a token economy system, is geared to the group and often is used in classrooms and res-

\section{Three Square Approach}

\section{Before}

Jim kicks Bill in the hall.

\section{Target}

Bill slaps Jim on back when he enters class.
After

Bill gets a detention.

\section{Four Square Approach}

\section{Before}

Jim kicks Bill in the hall.

\section{Target}

Bill slaps Jim on the back when he enters class.

\section{Bill gets a detention.}

Solutions
Give Jim a detention.
Apologize to Bill for being
unfair.
Have conference with
both boys.
Next time find out what
actually happened.

Five Square Approach

Before
Jim kicks Bill in the
hall.

\begin{tabular}{l}
\multicolumn{1}{c|}{ Target } \\
Bill slaps Jim on the \\
back when he enters \\
class. \\
\hline
\end{tabular}

\section{Solutions \\ Give Jim a detention. Apologize to Bill for being unfair.}

Have conference with boys.

Next time find out what actually happened. 
idential settings. A list of behaviors and reinforcers for the group is compiled so the individual operates within the system set up for the group. Typical classroom activities and reinforcers are listed in Figure 5.

The students receive points as the behaviors occur so the tallies result in the number of points the child has to spend. The student is free to spend the points any way he or she wishes.

Though these plans seem simple and straightforward, human behavior and its management are complex. When impulsivity, need for immediate gratification, and rapid satiation rates are involved, behavior management techniques may not work as well as expected. Cost-response techniques in which the students have the reward and only lose the reward through inappropriate behavior have been found to be effective for some students (Swanson, Kotkin, Pfiffner, \& McBurnett, 1992).

Another alternative is to use techniques that involve the student in the process. The student is given models of solutions to the identified problem and asked to come up with a workable solution. The student may use one of the models or generate a new solution. Role-playing solutions or alternative behaviors can also be helpful. Students brainstorm all the possible behavior choices for an identified situation, role-play each option and its consequences, and choose the best solution.

Even when new behaviors are learned, generalization of the behaviors has been difficult to achieve without additional intervention such as the technique Swanson and his colleagues have successfully developed (Swanson et al., 1992). The trainer was used as an effective generalization cue by having the trainer actually be present in the new setting to act as a stimulus to generalize the new behavior.

\section{Organizational Strategy Training}

Teachers need to tell students with attention disorders how to learn as well as what to learn without using complicated, step-by-step strategies that do not accommodate the characteristics of students with attention disorders and are not flexible enough to generalize easily to a variety of situations. Appropriate interventions should:

1. Be systematic to minimize judgment and organizational demands.

2. Be simple and dependable.

3. Be manipulative (active involvement).

4. Build the necessary base of information (not activate prior knowledge).

5. Identify missing skills.

6. Force conceptual understanding or recognition of instructional needs.

7. Be concrete and visual.

8. Provide advance organization so multiple passes through material is not required.

9. Help break down processes into manageable units.

10. Guide the learning process.

11. Force attention to critical detail.

12. Result in review systems consisting of the critical pieces of information.

13. Accommodate nonlinear or associational styles of thinking.

14. Guide memory storage and practice specific retrieval in a study system.

If interventions do not meet these criteria, the effectiveness of the approach will be diminished by the interaction of the characteristics of attention disorders and the characteris-

\section{Activities}

On time for class

Has materials

Completes work

Raises hand for question

Test grade $A$

Test grade $B$

Test grade $C$

Takes turn

Points
10
20
30
10
50
40
30
20

$\begin{array}{lc}\text { Reinforcers } & \text { Points } \\ \text { Prize bag } & 200 \\ \text { Computer time (15 min.) } & 100 \\ \text { Activity table (15 min.) } & 100 \\ \text { Conversation time (15 min.) } & 100 \\ \text { Daily Messenger } & 200 \\ \text { Listen to music } & 200 \\ \text { Library time (15 min.) } & 100\end{array}$

FIGURE 5

Typical Activities and Reinforcers 
tics of the situation or the academic task. The following strategies (Rooney, 1990) support attention, guide information processing, and facilitate memory storage/retrieval. They were designed to accommodate the cognitive and behavioral characteristics associated with attention deficit disorders.

\section{Content Reading}

For students with ADD, certain concerns related to content reading have to be addressed. These students have difficulty with the accuracy of prior knowledge and compilation of the critical detail that successful students attend to automatically. To do this, strategies that guide the selection of the appropriate detail must be taught, as opposed to approaches that define the process after selection of the important detail has taken place. To accomplish this, the student:

1. Reads the subtitle and the section under the subtitle. As the student is reading, he or she writes the names of people and places, and important numbers and terms on separate index cards. Only the word or number by itself should be on a card. For example, if the words Ireland, 2500 B.C. and Urquhart Castle were in a passage, each would appear on a separate card.

2. Returns to the subtitle and turns it into the best test question possible. The words of the subtitle must be in the question. He or she writes the question on one side of an index card and answers the question on the back of the same card.
3. Repeats steps 1 and 2 on all the sections to be covered, producing two types of cards, one with main idea questions and answers and the other with specific details.

4. Studies the cards by looking at them one by one. For the detail cards the student asks the question, "How is this related to the material?" or "What does this have to do with the material?" For the main idea cards the student tries to answer the question from memory.

If the student is not sure of an answer for any of the cards, the card is placed in one pile. If the student is sure of the answer, the card is placed in a second pile. The cards will be sorted into two piles, one called "not sure" and the other called "sure." The student sets the "sure" pile aside and continues working with the pile called "not sure." For the unknown detail cards, he or she goes back into the material or asks someone for the answer and writes the answer on the back of the card. The student reviews the detail cards as well as the main idea cards (which already have the answer on the back) until all cards are in the "sure" pile.

For a comprehensive review for semester examinations, all the cards are reviewed, as the system automatically has accumulated all the details and main ideas presented during the semester. The cumulative nature and the card-sort as a manipulative process support review and study, which is even more problematic for students with ADD if a long delay occurs between the instruction and the evaluation. A sample from a ninth-grade handout is presented in the ac-

\section{THE LOCH NESS MONSTER}

Over the years, people in all countries have been fascinated by reportings of monsters that seem to date from prehistoric times or the age of the dinosaurs. Sightings of the Abominable Snowman, Big Foot, and the Loch Ness Monster have intrigued journalists, explorers, and scientists for many years. Recently, new scientific equipment has focused renewed interest in the legend of the Loch Ness Monster.

\section{A DESCRIPTION OF LOCH NESS}

In Scotland lies a very famous lake called Loch Ness. The lake is about 24 miles long, about a mile wide, and approximately 650 feet deep. Overlooking the lake are several local castles such as the famous
Urquhart Castle and the Aldourie Castle. The presence of the castles adds a mystique to the area, which increases interest in the area. The main attraction of Loch Ness, however, is the reported presence of a huge, serpent-like monster named "Nessie."

\section{NESSIE}

The Loch Ness Monster may be the most famous sea serpent in the world. It is described as being 40 to 60 feet long with a head about the size of a horse's head. Its thin neck is about six feet long and is attached to a fat body with an eight-foot-long tail. The description is similar to a dinosaur known as the plesiosaurus. Scientists think that Nessie is a plesiosaurus that has survived since prehistoric times. 

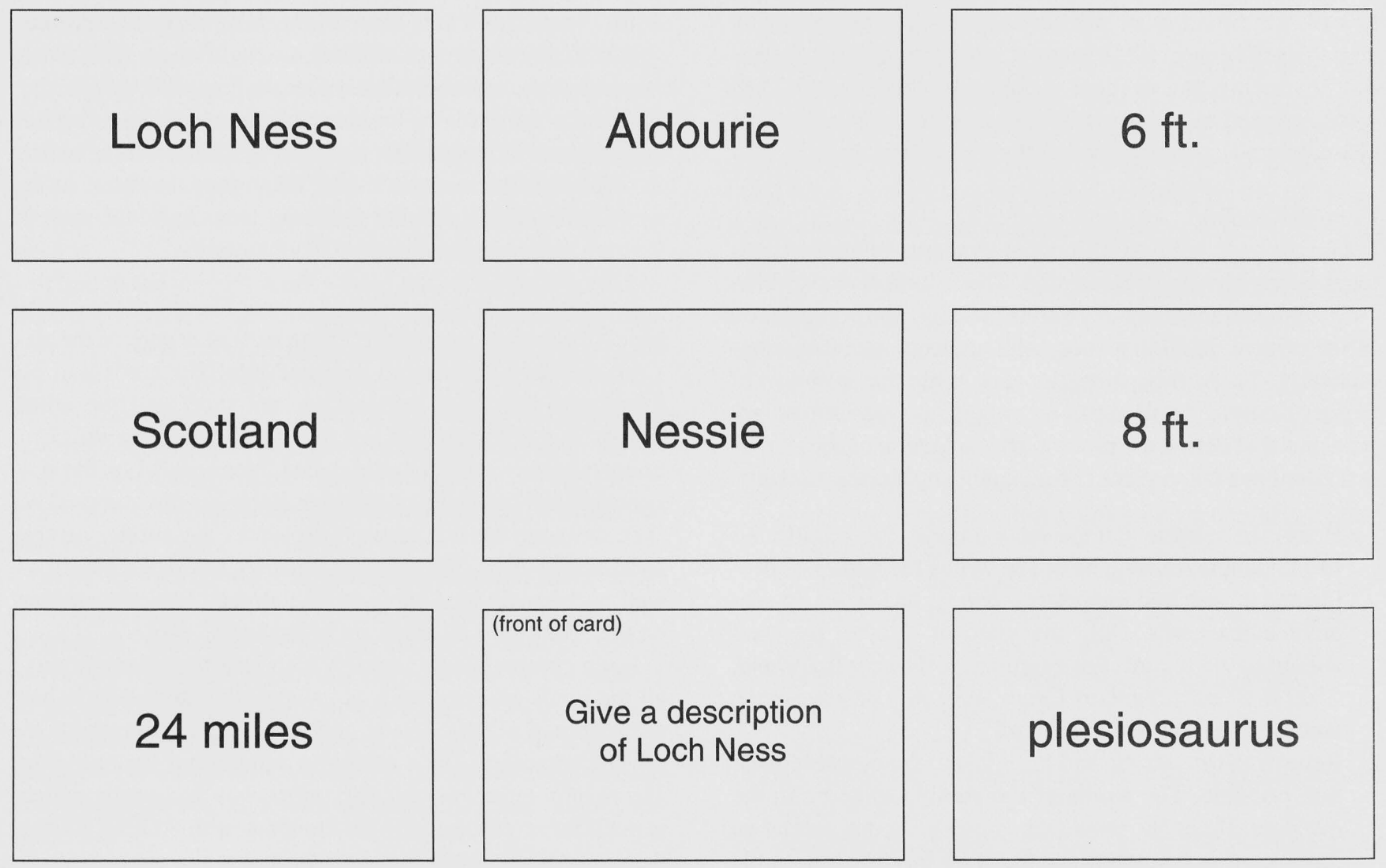

(front of card)

Give a description of Loch Ness

\section{plesiosaurus}

\section{$650 \mathrm{ft}$.}

(back of card above)

1. lake

2. Aldourie and Urquhart castles

3. 24 miles long

4. $650 \mathrm{ft}$. deep

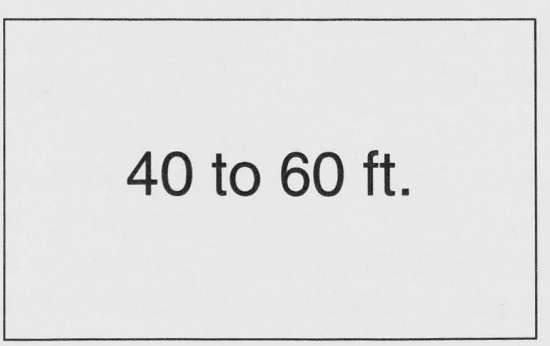

(back of card above)

1. serpent-like

2. 40-60 ft. long

3. plesiosaurus

4. long neck and tail 


\section{Title: Author:}
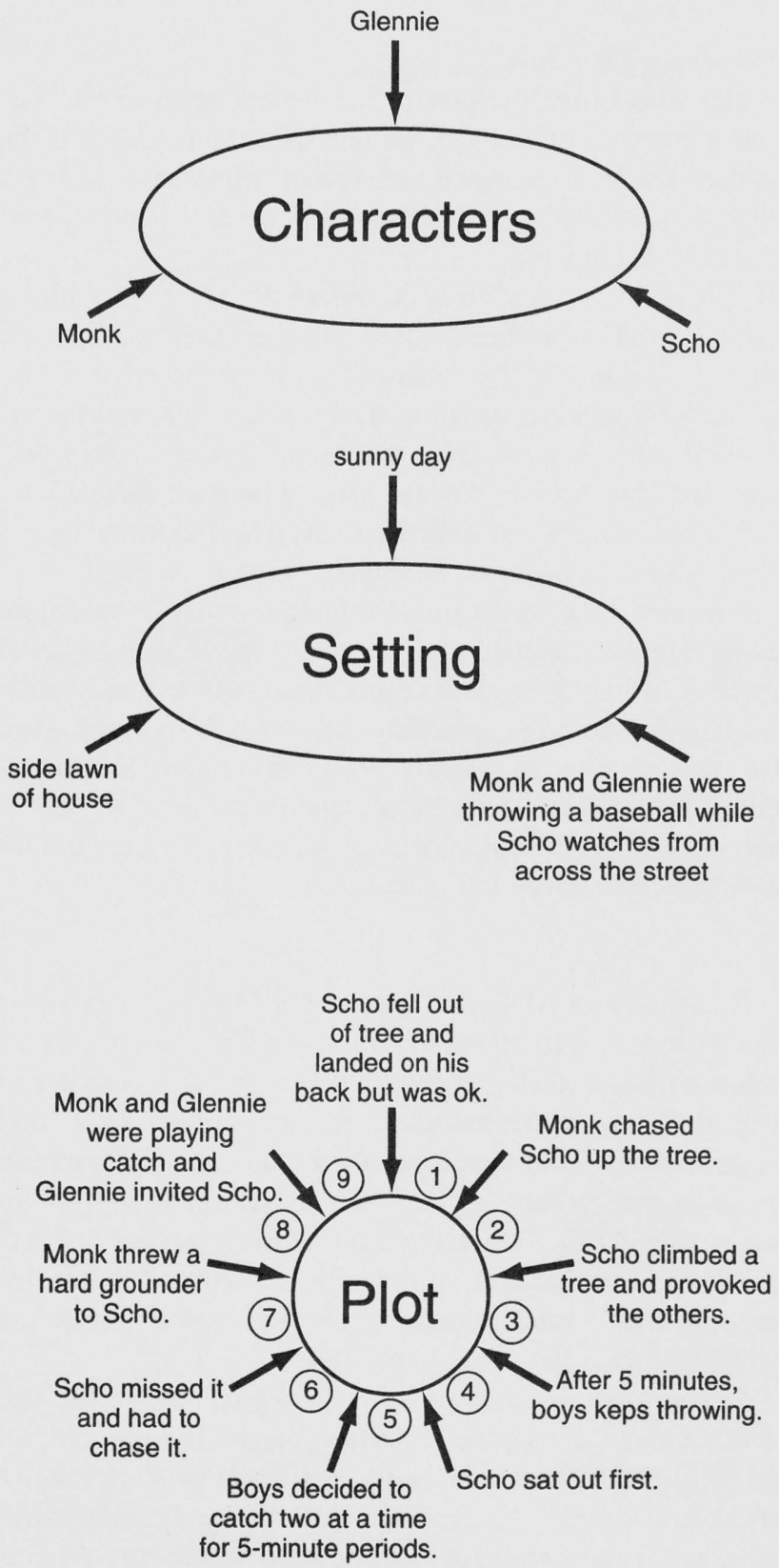

FIGURE 8

Sample Literature Wheels
1. Place the title at the top of a sheet of paper.

2. Draw five oval shapes (wheels) on the first sheet. Write start in the first oval and end or therefore in the last oval. Place a word, a phrase, or a sentence in the first wheel to identify the idea or ideas that will be used to start the paper (introduction). Write one main idea to be developed inside each of the three middle wheels. In the last wheel, mark end or therefore, write a word, a phrase, or a sentence to identify the conclusion.

3. Reproduce each oval on a separate sheet of paper. Around each oval attach all possible details, ideas, or thoughts related to the idea around the wheel in a spokelike fashion.

4. When all the ideas are around the appropriate wheels, number the ideas in the order they will be written about in the paper.

The strategy results in a set of six pages. The first page has the five-wheel overview, and each of the other pages has an individual wheel on it, as illustrated in Figure 9. The wheels can be used to develop an outline or to write a rough draft.

The wheels provide structure to brainstorm ideas in any order, organize information without excessive demands on memory, and sequence ideas as separate steps before the student actually produces the written language. The student can work on the material one wheel at a time without losing the organization. The number of wheels varies to meet the demands of the assignment:

Essay test One wheel with the question in the center and ideas to be developed attached around the wheel.

Paragraph Three wheels with the topic sentence in the first, the main idea in the second, and the clincher sentence in the third. The ideas are attached around the second wheel and numbered in sequential order.

Composition Five wheels-for introduction, three main ideas, and conclusion.

Research Paper Five basic wheels, but, for a long paper, additional sets of wheels in groups of three can be added.

\section{Mathematics}

Attentional deficits impact math performance in three basic ways: 


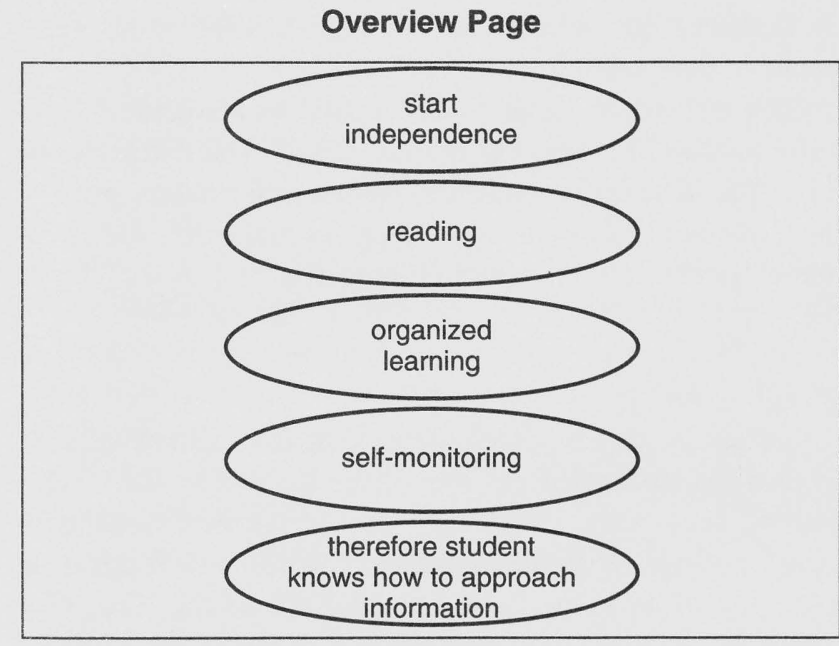

\section{Individual Pages}
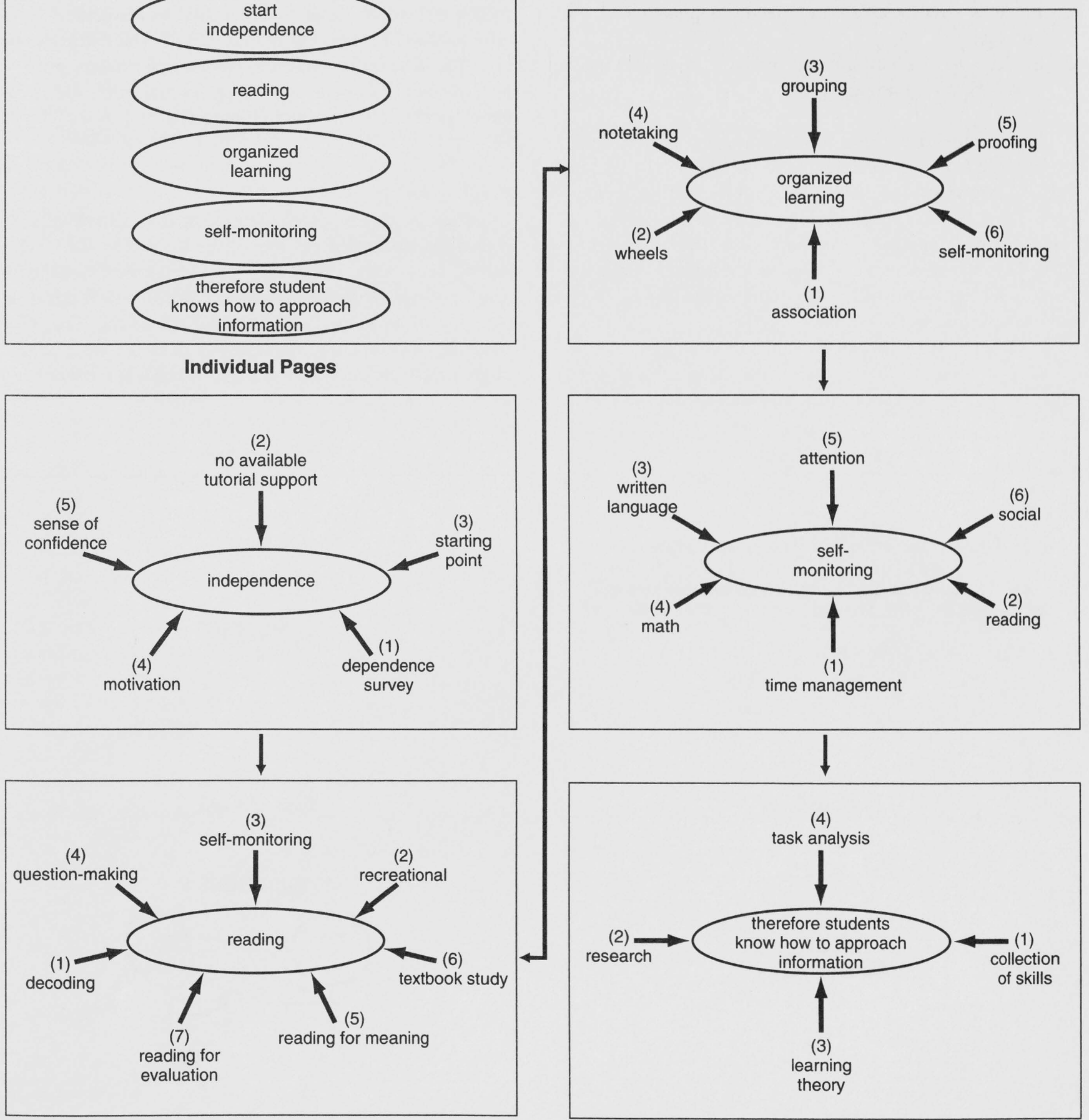

FIGURE 9

Visual Depiction of Writing Strategy 
1. Students have difficulty handling the sequential processing demands.

2. Students have trouble with specific application of the concept.

3. Students have a hard time attending to the details (such as sign of operation) involved.

To accommodate these weaknesses, application study cards made from the math textbook may help. The student uses the information at the beginning of the section or chapter to identify the concept being explained and writes the topic and page number in the book at the top of an index card. Then the student takes notes on the instructions in the book in his/her own words. The student makes up an original example and works out the example.

A teacher or tutor checks the student's example for accuracy. If the example has an error, the error is highlighted and corrected so the study cards draw the student's attention

\section{Front of Card}

\section{p. 52 First-degree equations having two variables}

A first-degree equation having two variables is one that can be written in this standard form.

$$
\begin{aligned}
A x+B y & =C \\
A B C & =\text { constants } \\
X \& Y & =\text { variables }
\end{aligned}
$$

\section{Back of Card}

$$
2 x+3 y=12
$$

to "careless errors" that have a high possibility of recurrence in the future.

This procedure supports conceptual understanding, specific application, and attention to detail. The cards can be used for frequent repetition to review information prior to new learning, as well as to promote automaticity. An example of a math card is given in Figure 10.

\section{Vocabulary}

Vocabulary weaknesses often stem from a lack of conceptual understanding or from the absence of visual images behind the words. To provide a visual base for a verbal concept, students write the vocabulary word to be learned on one side of an index card. On the back of the card, they write the definition and immediately draw a simple picture of the first association they made after reading the word and its definition. Figure 11 uses the example of the word bel-

\section{Front of Card}

\section{belligerent}

\section{Back of Card}

argumentative
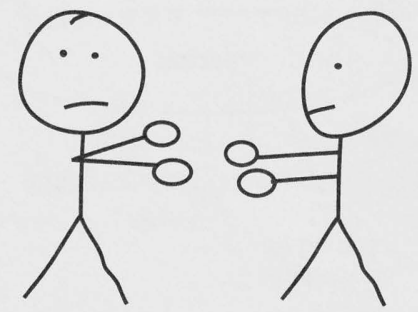

FIGURE 11

FIGURE 10

\section{Sample Vocabulary Card}


ligerent, meaning argumentative, and pulls up the image of two children fighting. The strategy produces a visual association that comes from the student's general knowledge base, so unknown information is linked to known information.

\section{Spelling}

The spelling strategy does not replace spelling instruction but does provide a structured way of processing words using a multisensory approach. The strategy should be used to learn spelling words, content area terms, or the spelling of vocabulary words. As with the vocabulary strategy, the spelling strategy uses index cards to maintain a cumulative review system. On the front of the card, the student:

1. Writes the correct spelling of the word.

2. Spells the word out loud.

3. Spells and writes the word in its parts.

4. Marks visual clues such as small words within the word.

Turns the card over and:

5. Writes the word from memory.

6. Marks the visual clues again.

7. Writes the word with eyes closed.

The strategy, illustrated in Figure 12, supports sequential processing as well as attention to detail, and it provides multisensory processing and utilizes global associative strengths. Words misspelled in writing should be emphasized over low-frequency words from lists.

\section{CONCLUSION}

Working with students who have attention disorders can be challenging, but it also can be extremely rewarding when interventions enable students to improve their behavior and academic performance. To be successful, teachers need to examine the characteristics of the disorder present in the individual student and be knowledgeable about the impact of these characteristics on behavior, performance, and instruction.

Techniques for observation and behavioral analysis allow the teacher to gain the insight necessary to understand the student and the dynamics of the situation. The tools of behavior management and organizational training enable the teacher to design interventions to accommodate individual needs. Observation and behavioral analysis must clarify the issues that need to be addressed in the intervention planning, and behavior management programs and academic strategies must take the identified characteristics and dynamics into account. This approach should produce "goodness of fit," which results in greater success for students with attentional disorders.

\section{REFERENCES}

Baddeley, A. D. (1986). Working memory. New York: Oxford Press. Broadbent, D. E. (1971). Decision and stress. New York: Academic Press. Goldstein, S., \& Goldstein M. (1990). Managing attention disorders in children. New York: John Wiley \& Sons.

Hallahan, D. P., Kneedler, R. D., \& Lloyd, J. W. (1982). Cognitive behavior modification techniques for learning disabled children: Self-instruction and self-monitoring. In J. D. McKinney \& L. Feagans, Cur-

\section{Front of Card}

believe

be lie ve

\section{believe}

believe

\section{Back of Card}

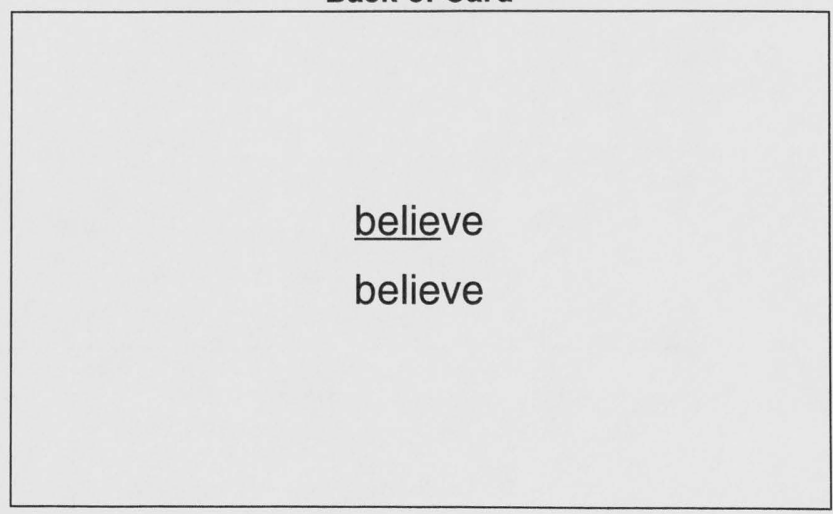

Sample Vocabulary Card 
rent topic in learning disabilities (Vol. 1, pp. 207-244). New York: Ablex Publishing.

Hallahan, D. P., Lloyd, J. W., Kosiewicz, M. M., Kauffman, J. M., \& Graves, A. W. (1979). Self-monitoring of attention as a treatment for a learning disabled boy's off-task behavior. Learning Disability Quarterly, 2, 24-32.

Hallahan, D. P., \& Reeve, R. E. (1980). Selective attention and distractibility. In B. K. Keogh (Ed.), Advances in special education (Vol. 1, pp. 141-181). Greenwich, CT: JAI Press.

Hallahan, D. P., Tarver, S. G., Kauffman, J. M., \& Graybeal, N. L. (1978). Selective attention abilities of learning disabled children under reinforcement and response cost. Journal of Learning Disabilities, 11, 42-51.

Halperin, J. M., Newcorn, J. H., Sharma, V, Healey, J. M., Wolf, L. E., Pascualvaca, D. M, \& Schwartz, S. (1990). Inattentive and noninattentive ADHD children: Do they constitute a unitary group? Journal of Abnormal Child Psychology, 18, 437-450.

Kahnehan, D. (1973). Attention and effort. Englewood Cliffs, NJ: Prentice Hall.

Kietzman, M. L., Spring, B., \& Zubin, J. (1980). Perception, cognition and information processing. In H. I. Kaplan \& B. J. Saddock (Eds.), Comprehensive textbook of psychiatry, 4, 157-178.

McIntyre, C. W., Murray, M. E., \& Blackwell, S. L. (1981). Visual search in learning disabled and hyperactive boys. Journal of Learning Disabilities, 14(3), 156-158.

Morris, R. J. (1985). Behavior modification with exceptional children. Glenview, IL: Scott, Foresman and Co.
Pettijohn, T. F. (1987). Psychology: A concise introduction. Guilford, CT: Dushkin Publishing Group.

Posner, N. I., \& Snyder, C. R. (1975). Attention and cognitive control. In R. Solso (Ed.), Information processing and cognition: The Loyola symposium. Hillsdale, NJ: Earlbaum Press.

Postle, D. (1988). The mid gymnasium. London: Macmillan.

Richards, G. P., Samuels, S., Turnure, J. E., \& Ysseldyke, J. E. (1990). Sustained and selective attention in children with learning disabilities. Journal of Learning Disabilities, 23(2), 129-135.

Rooney, K. J. (1990). Independent strategies for efficient study. Richmond, VA: Educational Enterprises.

Rooney, K. J., Hallahan, D. P., \& Lloyd, J. W. (1984). Self- recording of attention by learning disabled students in the regular classroom. Journal of Learning Disabilities, 17, 360-364.

Rosenthal, R., \& Allen, T. (1978). An examination of the attention arousal and learning dysfunctions of hyperactive children. Psychological Bulletin, 85, 689-716.

Swanson, J. M., Kotkin, R., Pfiffner, L., \& McBurnett, K. (1992). Schoolbased interventions for ADD students. CHADDER, 6(1), 8-9, 22.

Torgeson, J. K., Kistner, J. A., \& Morgan, S. (1987). Component processes in working memory. In J. Borkowski \& J. D. Day (Eds.), Memory and cognition in special children: Perspectives on retardation, learning disabilities and giftedness. Norwood, NJ: Ablex.

Zentall, S. S. (1983). Learning environments: A review of physical and temporal factors. Exceptional Education Quarterly, 4, 90-115.

\section{PERMISSIONS AND COPYRIGHT}

All rights are reserved. No part of this publication may be reproduced, photocopied, faxed, stored in a retrieval system, or transmitted, in any form or by any means, electronic, mechanical, recording or otherwise, without the prior written permission of the publisher.
Back issues are available for sale. Reproduction requires permission and payment of fees. It is illegal and a violation of Federal copyright law to reproduce this publication without permission. Direct all inquiries to the permissions editor. 